http://congress.cnsfederation.org/congress/societyprizes/

\title{
2018 Society Prize Winners
}

\section{Congratulations to the following CNSF members that have been awarded 2018 Society Prizes.}

\section{Be sure to attend the Grand Plenary session on Monday morning when they will present their work alongside our prestigious Plenary Guest speakers.}

Canadian Neurosurgical Society (CNSS)

K.G. McKenzie Memorial Prize for Basic Neuroscience Research

Winner: $\quad$ Christopher Ahuja

Abstract Title: SMaRT Human Neural Stem Cells to Degrade Scar and Optimize Regeneration after Traumatic Cervical Spinal Cord Injury

Canadian Neurosurgical Society (CNSS)

K.G. McKenzie Memorial Prize for Clinical Neuroscience Research

Winner: $\quad$ Amparo Wolf

Abstract Title: The Risk of Malignancy after Stereotactic Radiosurgery

Canadian Association of Child Neurology (CACN)

President's Prize

Winner: $\quad$ Abdulla Alawadhi

Abstract title: Immune Deficiencies/Dysregulations Underpinning Childhood Limbic Encephalitis: a case series and literature review

Canadian Neurological Society (CNS)

Andre Barbeau Memorial Prize for Basic Research

Winner: $\quad$ Saud Alhusaini

Abstract title: The Relationship Between Carotid Stenosis, Cerebral Cortex Structure and Cognitive Function at Age 73

Canadian Neurological Society (CNS)

Francis McNaughton Memorial Prize for Clinical Research

Winner: Natalie Parks

Abstract Title: A Population-based Study of "No Evident Disease Activity” (NEDA) in Multiple Sclerosis 